\title{
Caracterização de pacientes com sequelas após infecção pelo vírus chikungunya de acordo com a CIF
}

\author{
Characterization of patients with sequelae after chikungunya virus infection according \\ to the ICF
}

Jurandir da Silva Filho ${ }^{1}$, Lídia Ferreira da Silva ${ }^{1}$, Jullyane Maria Lima ${ }^{1}$, Mylena Cristina Ever de Almeida ${ }^{1}$, Mellina Monteiro Jacob², Suellen Alessandra Soares de Moraes²*

\begin{abstract}
${ }^{1}$ Bacharel em Fisioterapia; ${ }^{2}$ Doutora em Neurociências e Biologia Celular, Professora Adjunto do Instituto de Ciências
\end{abstract} da Saúde, da Universidade Federal do Pará (UFPA)

\begin{abstract}
Resumo
Objetivo: caracterizar segundo a Classificação Internacional de Funcionalidade, Incapacidade e Saúde (CIF), as sequelas apresentadas por pacientes após infecção pelo vírus chikungunya (CHIKV). Metodologia: estudo transversal e descritivo, realizado com 34 participantes, com diagnóstico sorológico e/ou clínico de infecção pelo CHIKV. As variáveis foram coletadas por meio da Escala Visual Analógica (EVA), Short Form Health Survey 36 (SF-36) e Medical Research Council (MRC), e relacionadas com os domínios da CIF para então classificá-las. Os dados foram tabulados em planilha Microsoft Excel 2013 com estatística descritiva calculada pelo programa GraphPad Prism 6. Os resultados foram apresentados como média e desvio padrão ou mediana e intervalo interquartil. Resultados: os resultados obtidos com a EVA foram caracterizados como moderada a grave deficiência, no SF-36 os domínios variaram de moderada a completa deficiência e no MRC todos os movimentos analisados corresponderam a ligeira deficiência. Conclusão: foi possível caracterizar alterações osteomioarticulares e a funcionalidade dos pacientes infectados pelo CHIKV e classificá-los dentro do contexto da $\mathrm{ClF}$, garantindo uma padronização para a descrição dos componentes relacionados à saúde desses pacientes.

Palavras-chave: Vírus Chikungunya. Febre Chikungunya. Classificação Internacional de Funcionalidade. Incapacidade e Saúde. Qualidade de vida. Força muscular.
\end{abstract}

\begin{abstract}
Objective: This study aimed to characterize the sequelae presented by patients after chikungunya virus (CHIKV) infection, using the International Classification of Functioning, Disability and Health (ICF). Methodology: Was made a descriptive cross-sectional study with 34 subjects with a serological and / or clinical diagnosis of CHIKV infection. The data were collected using the Visual Analogue Scale (VAS), Short Form Health Survey 36 (SF-36) and Medical Research Council (MRC), and were related and classified by the ICF domains. Data were arranged in Microsoft Excel 2013 and descriptive statistics was performed. Results were presented as mean and standard deviation or median and interquartile range. Results: VAS values were characterized from moderate to severe deficiency, SF-36 results showed the domains ranged from moderate to complete deficiency and in MRC data all movements analyzed were mild deficient. Conclusion: It was possible to characterize osteomioarticular changes and the functionality of CHIKV infected patients and to classify them within the context of the ICF, ensuring standardization for the description of health-related components of these patients. Key Words: Chikungunya virus. Chikungunya Fever. International Classification of Functioning. Disability and Health. Quality of Life. Muscle Strength.
\end{abstract}

\section{INTRODUÇÃO}

A chikungunya é uma arbovirose que consiste em uma doença febril aguda, caracterizada como artralgia potencialmente debilitante, sendo ocasionada pelo vírus chikungunya, do gênero Alphavirus. A transmissão ocorre, principalmente, através da picada de fêmeas do mosquito Aedes aegypti e Aedes albopictus infectados. Contudo, a transmissão por relação sexual, transmissão vertical e por transfusão sanguínea também já foi relatada na literatura ${ }^{1-3 .}$

Correspondente/Corresponding: *Suellen Alessandra Soares de Moraes - End: Rua Augusto Corrêa, 01 - Guamá. CEP 66075-110 - Tel: (91) 3201-8892 - E-mail: sualessandra@yahoo.com.br
O período intrínseco de incubação é em média de 3 a 7 dias, já o extrínseco chega a durar 10 dias. 0 período de viremia se inicia dois dias antes do surgimento dos sintomas, podendo perdurar por mais oito dias. Estudos mostram que até $70 \%$ dos indivíduos infectados pelo CHIKV são sintomáticos, sendo este percentual alto e significativo quando comparado a outras arboviroses ${ }^{1}$.

A doença pode evoluir em três fases: aguda, subaguda e crônica. Após o período de incubação tem início a fase aguda ou febril, que dura até o décimo quarto dia. Os indivíduos que persistem com dores articulares por até 3 meses são classificados na fase subaguda. Quando as dores articulares se prolongam além desse período são classificados na fase crônica ${ }^{4,5}$. 
A respeito dessa fase crônica, há uma crescente preocupação da comunidade científica com a persistência das manifestações clínicas, tais como artralgia crônica, diversos tipos de lesões musculoesqueléticas e fadiga, já que tais comprometimentos tendem a piorar sobremaneira a funcionalidade, a qualidade de vida e a saúde geral ${ }^{6-8}$.

A Classificação Internacional de Funcionalidade, Incapacidade e Saúde (CIF), faz parte da família das classificações internacionais desenvolvidas pela Organização Mundial da Saúde (OMS). Essa classificação é uma ferramenta útil para o conhecimento das condições de funcionalidade de uma pessoa, ponderando se está associada ou não a alguma doença, bem como avalia o ambiente nesse processo, considerando-o um facilitador ou barreira ${ }^{9,10}$.

A CIF é organizada em duas partes, cada qual contendo dois componentes: a primeira parte é chamada de "Funcionalidade e Incapacidade", integrada pelos componentes "Corpo" (classificação para o sistema orgânico e para as estruturas do corpo) e "Atividades e Participação". A segunda parte corresponde aos "Fatores contextuais", com os componentes "Fatores ambientais" e "Fatores pessoais" (este último não classificado na $\mathrm{CIF})^{11}$.

Os componentes da CIF podem ser expressos em termos positivos (funcionalidade) e negativos (incapacidade). Cada um desses componentes contém domínios, que por sua vez apresentam categorias, as quais são as unidades de classificação. As condições de saúde são registradas por meio de códigos apropriados às categorias, além do acréscimo de qualificadores. Estes últimos são códigos numéricos que especificam a magnitude ou extensão da incapacidade ou funcionalidade de determinada categoria, ou de que forma um fator ambiental facilita ou constitui um obstáculo ${ }^{11}$.

Considerando que os casos de chikungunya se mantiveram altos nos últimos anos e que o surgimento de sequelas nos pacientes afeta a ocupação, a vida social e a funcionalidade, implicando diretamente nos gastos públicos em saúde e previdência, faz-se necessário a classificação da saúde dos pacientes que apresentam sequelas pós infecção por CHIKV, levando a uma melhor caracterização, padronização e manejo desses pacientes, através de uma classificação internacional ${ }^{1,4}$.

$O$ presente estudo tem como objetivo caracterizar segundo a Classificação Internacional de Funcionalidade, Incapacidade e Saúde, as sequelas apresentadas por pacientes após infecção pelo vírus chikungunya.

\section{METODOLOGIA}

\section{DESIGN DO ESTUDO}

Trata-se de um estudo observacional de caráter transversal e descritivo. Os dados foram coletados por meio de avaliações realizadas no período de janeiro de 2018 a fevereiro de 2019.

\section{PROCEDIMENTOS ÉTICOS}

O estudo foi realizado na Faculdade de Fisioterapia e Terapia Ocupacional, Universidade Federal do Pará. Aprovado pelo comitê de ética em pesquisa do Instituto de Ciências da Saúde da Universidade Federal do Pará ICS/ UFPA sob o número de aprovação 1.593.170. A pesquisa seguiu as recomendações do Conselho Nacional de Ética em Pesquisa (CONEP), segundo RESOLUÇÃO 466/12. Todos os participantes assinaram o termo de consentimento livre e esclarecido

\section{PARTICIPANTES}

A amostra inicial foi composta por 49 pacientes submetidos à avaliação fisioterapêutica em um projeto de extensão universitária. Os critérios de inclusão consistiam em possuir confirmação sorológica ou clínica de infecção pelo vírus chikungunya, ter idade superior a 18 anos, ter realizado a avaliação completa e estar na fase subaguda ou crônica da infecção.

Com base nos critérios de inclusão, o número amostral foi reduzido para 34 pacientes, dentre os quais 19 apresentaram confirmação sorológica e 15 apenas o diagnóstico clínico para a infecção por CHIKV. Todos os pacientes residiam na região metropolitana de Belém e foram recrutados através de anúncios nas mídias eletrônicas.

\section{PROCEDIMENTO PARA COLETA DE DADOS}

Todos os participantes do estudo foram submetidos a avaliação fisioterapêutica. Na anamnese foram colhidas informações para a caracterização demográfica (idade e sexo); período de infecção; características clínicas do período inicial da infecção; diagnóstico clínico e/ou viral e exames complementares. $O$ exame físico consistiu em mensuração da força dos músculos adjacentes às principais articulações acometidas após a infecção, utilizando a escala Medical Research Council (MRC). Na MRC há variação de escore de zero a cinco, onde zero equivale a nenhuma contração muscular, e cinco equivale a contração muscular contra uma grande resistência manual aplicada pelo avaliador.

A sintomatologia da dor foi avaliada através da Escala Visual Analógica (EVA), com escore numérico variando de zero a dez, sendo zero nenhuma dor apresentada e dez a pior dor já sentida pelo paciente.

O questionário utilizado para a avaliação da qualidade de vida foi o Short Form Health Survey 36 (SF-36), que é composto por sete domínios: Capacidade Funcional; Limitação por aspectos físicos; Dor; Estado Geral de Saúde; Vitalidade; Aspectos sociais; Limitações por aspectos emocionais e Saúde mental. A pontuação varia de zero a cem, onde zero corresponde a pior qualidade de vida, e cem a melhor qualidade de vida.

A CIF foi relacionada com os resultados obtidos através da avaliação fisioterapêutica. No componente 
"Funções e Estruturas do Corpo" foram avaliados os seguintes domínios/capítulos da CIF para "Funções do Corpo": Funções sensoriais e de dor, Funções mentais e Funções musculares. No componente "Atividades e Participação" foram avaliados os domínios/capítulos da CIF: Vida doméstica e Interação e Relacionamentos interpessoais.

A qualificação na CIF varia de zero a quatro, onde zero representa nenhuma deficiência/dificuldade e quatro equivale a deficiência/dificuldade completa; além destes, apresenta os valores oito para "não especificado" e nove para "não aplicável". Para realizar a comparação das escalas e questionário com a CIF, foram utilizados escores baseados em estudos anteriores e na própria $\mathrm{CIF}^{10-12}$.

As características da CIF foram selecionadas de acordo com o maior nível de detalhamento possível para caracterizar com precisão a EVA, os Domínios do SF-36 e o MRC. Dois pesquisadores selecionaram de maneira independente os componentes e categorias da CIF que poderiam ser aplicados para caracterizar as articulações dolorosas, a força muscular e os domínios do questionário de qualidade de vida. Em caso de discordância, um terceiro pesquisador era requerido para resolver as contradições.

\section{ANÁLISE DOS DADOS}

Os dados foram tabulados em planilha do Microsoft Excel 2013, com estatística descritiva calculada por meio do programa GraphPad Prism 6. Os resultados foram apresentados como média e desvio padrão ou mediana e intervalo interquartil, por meio de tabelas.

\section{RESULTADOS}

Entre o período de janeiro de 2018 a fevereiro de 2019, foram avaliados 49 pacientes. Desses, foram excluídos cinco por apresentarem diagnóstico sorológico para zika ou dengue, três por estarem na fase aguda da doença e sete por não apresentarem diagnóstico sorológico e/ou clínico para CHIKV. No total, permaneceram 34 pacientes com o diagnóstico sorológico ou clínico de artrite séptica pelo vírus chikungunya. Observou-se a predominância do sexo feminino, correspondendo a 30 pacientes, frente a apenas 4 do sexo masculino. As idades variaram entre 28 e 70 anos, com média de 45,7 $\pm 12,18$ anos. No que concerne à fase de infecção, houve predominância da fase subaguda, com 18 casos. Os outros 16 casos compreendiam a fase crônica.
Para classificar os resultados de SF-36, EVA e MRC de acordo com a $\mathrm{CIF}$, foi realizada a equivalência entre os qualificadores e descritores quantitativos e qualitativos da CIF e os escores quantitativos e qualitativos dos instrumentos avaliativos citados. A comparação entre os qualificadores da CIF e os escores do SF-36 e do MRC, demonstrou uma relação inversamente proporcional. Já ao comparar os qualificadores da CIF com os escores da EVA, foi observada uma relação diretamente proporcional (Tabela 1).

Ao correlacionar os resultados da EVA com os capítulos da CIF, as articulações foram distribuídas da seguinte forma: para membros superiores, mãos e punhos foram dispostos na categoria b28014, e cotovelos e ombros alocados na categoria b28016; para membros inferiores, joelhos e tornozelos ficaram em b28015; e pés, sendo estes caracterizados por todas as articulações que os compõe, foram classificados na categoria b28016. Para o SF-36, os domínios Capacidade Funcional, Limitação por Aspectos Físicos, Dor, Estado Geral de Saúde, Vitalidade, Aspectos Sociais, Limitação por aspectos emocionais e Saúde Mental corresponderam, respectivamente, às categorias d2101, d6409, b2800, b, b1300, d799, b1529 e b1265. No que concerne ao MRC, analisando-se as áreas de principal acometimento (punhos, joelhos e tornozelos) foram selecionadas as categorias b7030 para punhos e tornozelos e b7031 para os joelhos, por envolver um grupo muscular maior (Tabela 2).

A intensidade da dor pela EVA e os qualificadores da $\mathrm{CIF}$ correspondentes, assim como, a frequência de articulações acometidas, são mostrados na Tabela 3. A maioria das articulações apresentou moderada deficiência. Entretanto, as articulações do joelho direito e esquerdo apresentaram grave deficiência, com qualificadores da CIF igual a 3 (50-95\% de deficiência), e EVA igual a 7 (dor intensa), indicando a maior deficiência apresentada.

Quanto a qualidade de vida, verificou-se que as sequelas após infecção por CHIKV também causam grande impacto, sobretudo nos domínios de "limitação por aspectos físicos" e "limitação por aspectos emocionais", cuja pontuação foi 0 para ambos. $\mathrm{Na} \mathrm{CIF,} \mathrm{esses} \mathrm{domí-}$ nios corresponderam ao qualificador $4(96-100 \%$ de deficiência), indicando deficiência completa (Tabela 4).

Na tabela 5 são demonstradas as principais articulações avaliadas pelo teste de força muscular do MRC e sua classificação qualitativa na $\mathrm{CIF}$, bem como suas medianas e intervalos interquartis, observando-se que todas as articulações avaliadas foram classificadas no qualificador da CIF como ligeira deficiência. 
Tabela 1 - Relação entre o qualificador do descritor quantitativo e qualitativo da CIF e a EVA, SF-36 e o MRC.

\begin{tabular}{|c|c|c|c|c|c|c|c|c|}
\hline $\begin{array}{c}\text { Qualificador } \\
\text { da CIF }\end{array}$ & $\begin{array}{c}\text { Descritor } \\
\text { quantitativo } \\
\text { da CIF }\end{array}$ & $\begin{array}{c}\text { Descritor } \\
\text { Qualitativo } \\
\text { da CIF }\end{array}$ & $\begin{array}{c}\text { Escore } \\
\text { EVA }\end{array}$ & $\begin{array}{c}\text { Escore } \\
\text { Qualitativo EVA }\end{array}$ & $\begin{array}{l}\text { Escore SF } \\
-36\end{array}$ & $\begin{array}{c}\text { Escore } \\
\text { Qualitativo } \\
\text { SF-36 }\end{array}$ & $\begin{array}{c}\text { Escore } \\
\text { MRC }\end{array}$ & $\begin{array}{c}\text { Escore Qualitativo } \\
\text { MRC }\end{array}$ \\
\hline 0 & $0-4 \%$ & $\begin{array}{l}\text { Nenhuma } \\
\text { deficiência }\end{array}$ & 0 & Nenhuma dor & $96-100$ & Maior & 5 & $\begin{array}{l}\text { Movimento contra } \\
\text { grande resistência }\end{array}$ \\
\hline 1 & $5-24 \%$ & $\begin{array}{l}\text { Ligeira } \\
\text { deficiência }\end{array}$ & $1-3$ & Dor Leve & $76-95$ & Boa & 4 & $\begin{array}{l}\text { Movimento contra } \\
\text { leve resistência }\end{array}$ \\
\hline 2 & $25-49 \%$ & $\begin{array}{l}\text { Moderada } \\
\text { deficiência }\end{array}$ & $4-6$ & Dor Moderada & $51-75$ & Regular & 3 & $\begin{array}{l}\text { Movimento contra } \\
\text { a gravidade }\end{array}$ \\
\hline 3 & $50-95 \%$ & $\begin{array}{l}\text { Grave } \\
\text { deficiência }\end{array}$ & $7-9$ & Dor Intensa & $5-50$ & Baixa & 2 & $\begin{array}{l}\text { Movimento sem } \\
\text { resistência da } \\
\text { gravidade }\end{array}$ \\
\hline 4 & $96-100 \%$ & $\begin{array}{l}\text { Deficiência } \\
\text { completa }\end{array}$ & 10 & Máxima dor & $0-4$ & Pior & $0-1$ & Sem movimento \\
\hline
\end{tabular}

CIF: Classificação Internacional de Funcionalidade, Incapacidade e Saúde; EVA: Escala Visual analógica; SF-36: Short Form Health Survey 36; MRC: Medical Research Council.

Fonte: Autoria própria

Tabela 2 - Descrição das categorias da CIF relacionadas com achados da EVA das articulações (dor), domínios do SF-36 (qualidade de vida) e achados no MRC (força).

\begin{tabular}{|c|c|c|}
\hline $\begin{array}{l}\text { EVA, Domínios do SF-36 } \\
\text { e MRC }\end{array}$ & $\begin{array}{l}\text { Categorias } \\
\text { da CIF }\end{array}$ & Descrição da Categoria \\
\hline $\begin{array}{l}\text { Dor na mão D e E } \\
\text { Dor no punho D e E } \\
\text { Dor no cotovelo D e E } \\
\text { Dor no ombro D e E }\end{array}$ & $\begin{array}{l}\text { b28014 } \\
\text { b28016 }\end{array}$ & $\begin{array}{l}\text { Dor em membro superior: sensação desagradável sentida em um ou nos dois membros superiores, } \\
\text { incluindo as mãos, que indica lesão potencial ou real em alguma estrutura do corpo. } \\
\text { Dor nas articulações: sensação desagradável sentida em uma ou mais articulações, grandes ou } \\
\text { pequenas, que indica lesão potencial ou real em alguma estrutura do corpo. }\end{array}$ \\
\hline $\begin{array}{l}\text { Dor no joelho D e E } \\
\text { Dor no tornozelo D e E } \\
\text { Dor no pé D e E }\end{array}$ & $\begin{array}{l}\text { b28015 } \\
\text { b28016 }\end{array}$ & $\begin{array}{l}\text { Dor em membro inferior: sensação desagradável sentida em um ou nos dois membros inferiores, } \\
\text { incluindo os pés, que indica lesão potencial ou real em alguma estrutura do corpo. } \\
\text { Dor nas articulações: sensação desagradável sentida em uma ou mais articulações, grandes ou } \\
\text { pequenas, que indica lesão potencial ou real em alguma estrutura do corpo. }\end{array}$ \\
\hline Capacidade funcional & d2101 & $\begin{array}{l}\text { Realizar uma tarefa complexa: preparar, iniciar e organizar o tempo e o espaço necessários para } \\
\text { uma tarefa complexa com dois ou mais componentes, que pode ser realizada em sequência ou em } \\
\text { simultâneo, como por exemplo, arrumar os móveis na própria casa ou fazer os deveres escolares. }\end{array}$ \\
\hline $\begin{array}{l}\text { Limitação por aspectos } \\
\text { físicos }\end{array}$ & d6409 & Realizar as tarefas domésticas, não especificadas. \\
\hline Dor & b2800 & $\begin{array}{l}\text { Dor generalizada: sensação desagradável sentida em todo o corpo que indica lesão potencial ou } \\
\text { real em alguma estrutura do corpo }\end{array}$ \\
\hline Estado geral de saúde & B & $\begin{array}{l}\text { Funções do corpo são as funções fisiológicas dos sistemas orgânicos (incluindo as funções } \\
\text { psicológicas). }\end{array}$ \\
\hline Vitalidade & b1300 & Nível de energia funções mentais que produzem vigor e força. \\
\hline Aspectos sociais & d799 & Interações e relacionamentos interpessoais, não especificados. \\
\hline $\begin{array}{l}\text { Limitação por aspectos } \\
\text { emocionais }\end{array}$ & b1529 & Funções emocionais, não especificadas. \\
\hline Saúde Mental & b1265 & $\begin{array}{l}\text { Otimismo: funções mentais que produzem um temperamento pessoal alegre, dinâmico e cheio } \\
\text { de esperança, em contraste com ser desanimado, triste e sem esperança. }\end{array}$ \\
\hline Flexão De Punho D e E & b7030 & $\begin{array}{l}\text { Força de músculos isolados e grupos musculares funções relacionadas com a força gerada pela } \\
\text { contração de músculos específicos e isolados e grupos musculares }\end{array}$ \\
\hline Flexão de Joelho D e E & b7031 & $\begin{array}{l}\text { Força dos músculos de um membro funções relacionadas com a força gerada pela contração dos } \\
\text { músculos e grupos musculares do membro superior ou do membro inferior }\end{array}$ \\
\hline Extensão De Joelho D e E & b7031 & $\begin{array}{l}\text { Força dos músculos de um membro funções relacionadas com a força gerada pela contração dos } \\
\text { músculos e grupos musculares do membro superior ou do membro inferior }\end{array}$ \\
\hline $\begin{array}{l}\text { Dorsiflexão De Tornozelo } \\
\text { D e E }\end{array}$ & b7030 & $\begin{array}{l}\text { Força de músculos isolados e grupos musculares funções relacionadas com a força gerada pela } \\
\text { contração de músculos específicos e isolados e grupos musculares }\end{array}$ \\
\hline $\begin{array}{l}\text { Flexão Plantar Tornozelo } \\
\text { D e E }\end{array}$ & b7030 & $\begin{array}{l}\text { Força de músculos isolados e grupos musculares funções relacionadas com a força gerada pela } \\
\text { contração de músculos específicos e isolados e grupos musculares }\end{array}$ \\
\hline
\end{tabular}

CIF: Classificação Internacional de Funcionalidade, Incapacidade e Saúde; EVA: Escala Visual Analógica; D: direita; E: esquerda; mão: articulações metacarpofalangeanas, interfalangeanas proximais, região tenar e hipotenar.

Fonte: Autoria Própria 
Tabela 3 - Distribuição de frequência de acometimento nas principais articulações dolorosas e valores da EVA, CIF e o descritor qualitativo da CIF.

\begin{tabular}{lcrrl}
\hline Principais articulações acometidas & $\begin{array}{c}\text { Frequência } \\
\text { (número) }\end{array}$ & $\begin{array}{c}\text { Mediana - IQR da } \\
\text { EVA }\end{array}$ & $\begin{array}{c}\text { Mediana - IQR da } \\
\text { CIF }\end{array}$ & $\begin{array}{c}\text { Descritor Qualitativo } \\
\text { da CIF }\end{array}$ \\
\hline Mão Direita & 25 & $5(4-7)$ & $2(2-2,5)$ & Moderada deficiência \\
Mão Esquerda & 22 & $6(4,75-8)$ & $2(2-3)$ & Moderada deficiência \\
Punho Direito & 23 & $6(4,5-8)$ & $2(2-3)$ & Moderada deficiência \\
Joelho Direito & 21 & $7(5-8)$ & $3(2-3)$ & Grave deficiência \\
Joelho Esquerdo & 20 & $7(5-8)$ & $3(2-3)$ & Grave deficiência \\
Tornozelo Direito & 25 & $6(4,75-8)$ & $2(2-3)$ & Moderada deficiência \\
Tornozelo Esquerdo & 21 & $6(4,75-8)$ & $2(2-3)$ & Moderada deficiência \\
\hline
\end{tabular}

EVA: Escala visual Analógica; CIF: Código Internacional de Funcionalidade; IQR: intervalo Interquartil.

Fonte: Autoria Própria

Tabela 4 - Valores dos Domínios do SF-36, da CIF e o descritor qualitativo da CIF.

\begin{tabular}{lccl}
\hline \multicolumn{1}{c}{ Domínios do SF-36 } & $\begin{array}{c}\text { Mediana - IQR do } \\
\text { SF-36 }\end{array}$ & $\begin{array}{c}\text { Mediana - IQR } \\
\text { da CIF }\end{array}$ & $\begin{array}{c}\text { Descritor Qualitativo } \\
\text { da CIF }\end{array}$ \\
\hline Capacidade Funcional & $30(25-60)$ & $3(2-3)$ & Grave deficiência \\
Limitação por aspectos físicos & $0(0-25)$ & $4(3-4)$ & Deficiência completa \\
Dor & $31(20-41)$ & $3(3-3)$ & Grave deficiência \\
Estado Geral de Saúde & $47(37-60)$ & $3(2-3)$ & Grave deficiência \\
Vitalidade & $40(25-60)$ & $3(2-3)$ & Grave deficiência \\
Aspectos sociais & $50(25-75)$ & $3(2-3)$ & Grave deficiência \\
Limitação por aspectos emocionais & $0(0-66,6)$ & $4(2-4)$ & Deficiência completa \\
Saúde Mental & $56(44-72)$ & $2(2-3)$ & Moderada deficiência \\
\hline
\end{tabular}

SF-36: Short Form Health Survey 36; CIF: Código Internacional de Funcionalidade; IQR: intervalo Interquartil.

Fonte: Autoria Própria

Tabela 5 - Valores do MRC, da CIF e o descritor qualitativo da CIF.

\begin{tabular}{lccc}
\hline \multicolumn{1}{c}{ Principais articulações Avaliadas } & $\begin{array}{c}\text { Mediana - IQR do } \\
\text { MRC }\end{array}$ & $\begin{array}{c}\text { Mediana - IQR } \\
\text { da CIF }\end{array}$ & $\begin{array}{c}\text { Descritor Qualitativo } \\
\text { da CIF }\end{array}$ \\
\hline Flexão De Punho Direito & $4(3,25-4)$ & $1(1-1,75)$ & Ligeira deficiência \\
Flexão De Punho Esquerdo & $4(4-4)$ & $1(1-1)$ & Ligeira deficiência \\
Flexão De Joelho Direito & $4(4-5)$ & $1(0-1)$ & Ligeira deficiência \\
Flexão De Joelho Esquerdo & $4(4-5)$ & $1(0-1)$ & Ligeira deficiência \\
Extensão De Joelho Direito & $4(4-5)$ & $1(0-1)$ & Ligeira deficiência \\
Extensão De Joelho Esquerdo & $4(4-5)$ & $1(0-1)$ & Ligeira deficiência \\
Dorsiflexão De Tornozelo Direito & $4(3-4)$ & $1(1-2)$ & Ligeira deficiência \\
Dorsiflexão De Tornozelo Esquerdo & $4(3-4)$ & $1(1-2)$ & Ligeira deficiência \\
Flexão Plantar Tornozelo Direito & $4(3-5)$ & $1(0-2)$ & Ligeira deficiência \\
Flexão Plantar Tornozelo Esquerdo & $4(3-5)$ & $1(0-2)$ & Ligeira deficiência \\
\hline
\end{tabular}

MRC: Medical Research Council; CIF: Código Internacional de Funcionalidade; IQR: intervalo Interquartil.

Fonte: Autoria Própria 


\section{DISCUSSÃO}

Trata-se do primeiro estudo que analisou a funcionalidade geral dos pacientes com sequelas após a infecção pelo vírus chikungunya, utilizando ferramentas validadas e relacionando-as com a CIF. Foram analisados os déficits e as consequências na força muscular, na sensação de dor e na qualidade de vida desses pacientes, assim como, a extensão das sequelas e os impactos na vida pessoal e profissional, como demonstrado pelas limitações funcionais e sociais. Segundo os resultados deste estudo, observa-se um comprometimento, segundo a $\mathrm{CIF}$, na força muscular (leve deficiência) e na qualidade de vida (deficiência/dificuldade completa em alguns domínios), além da sensação de dor configurar-se como deficiência grave em algumas articulações.

Dos 34 participantes selecionados para o estudo, a maioria era do sexo feminino, o que corrobora com os estudos de Silva et al. ${ }^{4} \mathrm{e}$ Thibervill et $a . .^{13}$, os quais mostram que as mulheres são mais propensas a progressão para a cronicidade da doença. A faixa etária afetada, no presente estudo, foi de 28 a 70 anos, com média de 45,7 anos. A chikungunya, no seu estágio crônico, caracteriza os pacientes com poliartralgia persistente e incapacitante conforme descrito nos estudos de Javelle ${ }^{14}$ e Mathew ${ }^{15}$. Essa doença repercute em diversas áreas, pois, além das suas consequências diretas, a abstenção ao trabalho e escola geram altos custos financeiros, algo preocupante dado o potencial epidêmico do vírus ${ }^{16}$. Estudos anteriores confirmam que nas Américas a média de idade de pessoas que fazem parte do grupo de risco é maior que 45 anos, uma faixa etária ainda na fase produtiva, a qual gera grandes gastos para a economia ${ }^{17}$.

A CIF é um modelo internacional para organizar e registrar informações sobre funcionalidade e incapacidade de forma padronizada e conceitual, definindo e mensurando a incapacidade por meio de classificações e códigos. ${ }^{18}$ Assim, após a coleta e análise dos dados, para fazer a comparação entre os valores das escalas e os qualificadores da CIF, utilizou-se como base o estudo de Fréz et al. ${ }^{12}$ Este sugere valores de escore do SF-36 para comparação com a CIF. Nesse sentido, segundo Fréz et al. ${ }^{12}$, quanto maior os valores de escore melhor é a qualidade de vida. Todavia, na $\mathrm{CIF}$, valores maiores representam uma deficiência grave, mostrando uma relação inversa entre ambos.

Para a utilização do MRC, o mesmo raciocínio foi seguido, já que não foram encontrados na literatura estudos que correlacionassem essa escala aos qualificadores da CIF. Portanto, o presente estudo sugere a utilização dos valores apresentados na Tabela 2, a qual demonstra que os escores do MRC são inversamente proporcionais aos valores da CIF. Já o uso dos escores da EVA, foi baseado nos valores utilizados no estudo de Zhang et al. ${ }^{19}$, com variação apenas no valor máximo. No presente estudo, foi considerado o valor 10 como máxima dor, que, ao ser comparado com a CIF, sugere uma deficiência completa, sendo estes valores diretamente proporcionais.
Para a categorização da EVA e do SF-36, observou-se que, de acordo com a CIF, existiam definições mais diretas e específicas para cada uma das áreas/articulações acometidas. Entretanto, no intuito de facilitar a classificação, optou-se por selecionar categorias que fossem abrangentes, a fim de delimitar os descritores, sem comprometer o nível de compreensão de cada aspecto ou item analisado. Desta forma, para membros superiores, as categorias da CIF b28014 e b28016 foram as mais abrangentes e que melhor se correlacionaram com a EVA e o SF-36. O mesmo raciocínio foi aplicado às categorias selecionadas para membros inferiores, b28015 e b28016.

O mesmo critério de abrangência foi aplicado aos domínios do SF-36. Logo, Capacidade Funcional, Limitação por Aspectos Físicos, Dor, Estado Geral de Saúde, Vitalidade, Aspectos Sociais, Limitação por aspectos emocionais e Saúde Mental corresponderam, respectivamente a, d2101, d6409, b2800, b, b1300, d799, b1529 e b1265. Outro estudo avaliou condição semelhante, mas com a população alvo constituída por pacientes com osteoartrite (OA). Os autores investigaram a confiabilidade e validade do constructo e potencial de mensuração de um core set abrangente da CIF para OA (Comprehensive Core Set of $A O)$. Seus resultados, a partir da utilização de escalas validadas, com a combinação da análise de Rasch, demonstraram que o core set é válido e confiáve ${ }^{20}$.

No que concerne ao MRC, a categorização da CIF para as principais áreas acometidas na população estudada, obteve os códigos b7030 (Força de músculos isolados e grupos musculares: funções relacionadas com a força gerada pela contração de músculos específicos e isolados e grupos musculares) para flexão de punho, dorsiflexão e flexão plantar de tornozelo; e b7031 (Força dos músculos de um membro: funções relacionadas com a força gerada pela contração dos músculos e grupos musculares do membro superior ou do membro inferior) para flexão e extensão de joelho.

As principais articulações acometidas por dor nos pacientes deste estudo foram, mão direita e tornozelo direito, porém os joelhos foram as articulações com maior gravidade quando correlacionado ao grau de deficiência segundo a CIF. Esses dados reforçam os achados de um estudo anterior, ${ }^{21}$ no qual, após avaliarem 258 pacientes, os autores identificaram as articulações do joelho, tornozelo, punho e dedos da mão como as que apresentaram maior frequência de acometimento entre a população do estudo. No mesmo estudo, observou-se que a dificuldade em deambular foi um dos comprometimentos mais significantes no público analisado, afetando $82,53 \%$ dos pacientes. Além disso, os estudos de Souza et al. ${ }^{22}$ também corroboram com nossos achados, no qual o nível de dor em mulheres na fase crônica da infecção pelo vírus chikungunya, variaram de moderado a grave e as articulações mais afetadas foram tornozelos e mãos.

O SF-36 é um instrumento que tem a capacidade de identificar por meio de cálculos estatísticos eficientes, diferenças nos aspectos clínicos e sociais na condição de 
saúde de indivíduos acometidos por alguma patologia. Neste sentido, no escore de pontuação do questionário, quanto maior for a pontuação melhor a qualidade de vida ${ }^{23}$. Assim, de acordo com os valores obtidos, foi constatado que os pacientes apresentavam, segundo o SF-36, comprometimento significativo na qualidade de vida, variando entre valores de 0 nos domínios Limitação por Aspectos Físicos e Emocionais, até 57 no domínio Saúde Mental. Ao correlacionar essas informações com a $\mathrm{ClF}$, notou-se que os qualificadores apontaram que as limitações variaram de moderada a grave deficiência, o que demonstra o grau de comprometimento funcional e social que pode ser provocado pela chikungunya.

Os pacientes deste estudo apresentaram limitações correspondentes a, pelo menos, $50 \%$ do considerado normal. Outros estudos sobre qualidade de vida em pacientes com OA, cujas manifestações clínicas compartilham semelhanças com os achados apresentados, apontam que as principais queixas desses indivíduos estão relacionadas a realização de atividades simples do dia a dia e a atividades de recreação, as quais podem ficar extremamente comprometidas. Nesse aspecto, fica claro o quanto esses fatores influenciam na qualidade de vida ${ }^{24,25}$.

São características comuns da infecção por CHIKV a poliartralgia incapacitante, artrite e mialgia. Isso pode dificultar na distinção entre esta doença e a dengue. No entanto, uma característica diferencial é o acometimento musculoesquelético recorrente em articulações periféricas e a longa permanência dos sintomas após a infecção aguda ${ }^{26}$. No presente estudo, após a análise das articulações mais acometidas, confirmamos que as articulações de mão, punho e tornozelo foram as acometidas com maior frequência e grau de comprometimento.

Por meio da relação dos qualificadores da CIF com o grau de força da musculatura adjacente às articulações afetadas, foi identificado uma ligeira deficiência. Nesse aspecto, infere-se que a capacidade da força muscular é limitada principalmente pela dor, visto que, na fase tardia, a artralgia ou a dor musculoesquelética podem se tornar mais frequentes, interferindo diretamente na qualidade de vida do indivíduo ${ }^{5}$.

As limitações do presente estudo se deram por número amostral reduzido, que pode diminuir seu impacto; a dificuldade na confirmação diagnóstica sorológica, as faixas etárias distintas da população, a diferença na composição da amostra quanto ao gênero, além do pioneirismo do estudo, cuja escassez de pesquisas relacionadas com análise funcional de pacientes infectados pelo CHIKV foi um fator de dificuldade. Nesse sentido, propomos que sejam realizados outros trabalhos com a contínua utilização da CIF e com maior número de pacientes com sequelas do CHIKV.

\section{CONCLUSÃO}

Foi possível caracterizar as alterações osteomioarticulares e a funcionalidade dos pacientes infectados pelo vírus chikungunya, classificando-os dentro do contexto da CIF e garantindo uma padronização para a descrição dos componentes relacionados à saúde desses pacientes.

\section{REFERÊNCIAS}

1. BRASIL. Ministério da Saúde. Secretaria de Vigilância em Saúde. Departamento de Vigilância das Doenças Transmissíveis. Chikungunya: manejo clínico. Brasília: Ministério da Saúde. Secretaria de Vigilância em Saúde. Departamento de Vigilância das Doenças Transmissíveis, 2017. p. 6-13. Disponível: http://bvsms.saude.gov.br/bvs/publicacoes/ chikungunya_manejo_clinico.pdf. Acesso em: 15 mar. 2019.

2. HSU, C. H. et al. Risk factors for hospitalization of patients with chikungunya virus infection at sentinel hospitals in Puerto Rico. PLos negl. trop. dis., San Francisco, v. 13, n. 1, jan. 2019. Disponível em: https:// journals. plos.org/plosntds/article?id=10.1371/journal. pntd. 0007084 . Acesso em: 17 mar. 2019. DOI: 10.1371/journal.pntd.0007084.

3. SILVA-FILHO, E. et al. Neuromodulation treats Chikungunya arthralgia: a randomized controlled trial. Sci. Rep., [s.I], v. 8, n. 16010. oct. 2018. Disponível em: https://www.nature.com/articles/s41598-018-34514-4. Acesso em: 15 Mar. 2019. DOI:10.1038/s41598-018-34514-4

4. SILVA, N. M. da et al. Vigilância de chikungunya no Brasil: desafios no contexto da Saúde Pública. Epidemiol. serv. saúde, Brasília, v. 27, n. 3, set. 2018. Disponível em: http://www.scielo.br/scielo.php?script=sci_ arttext\&pid=S2237-96222018000300301\&lng=pt\&nrm=iso\&tlng=pt. Acesso em: 05 Mar. 2019. DOI: 10.5123/s1679-49742018000300003.

5. CASTRO, A. P. C. R.; LIMA, R. A.; NASCIMENTO, J. S.; Chikungunya: vision of the pain clinician. Revista dor, São Paulo, v. 17, n. 4, p. 299-302, Dec. 2016. Disponivel em: http://www.scielo.br/scielo. php?pid=S1806-00132016000400299\&script=sci_abstract\&tlng=pt. Acesso em: 07 Mar. 2019. DOI: 10.5935/1806-0013.20160093.

6. ZAID, A. et al. Review: Chikungunya arthritis: implications of acute and chronic inflammation mechanisms on disease management. Arthritis rheumatol., Brasília, v. 70, n. 04, p. 484-495. Mar. 2018. Disponível em: https://onlinelibrary.wiley.com/doi/full/10.1002/art.40403. Acesso em: 23 Mar. 2019. doi:10.1002/art.40403

7. VEGA F. L. R. et al. Emergence of chikungunya and Zika in a municipality endemic to dengue, Santa Luzia, MG, Brazil, 2015-2017. Rev. Soc. Bras. Med. Trop., Uberaba, v. 52, e-20180347,

2019. Disponível em: http://www.scielo.br/scielo.php?script=sci_ abstract\&pid=S0037-86822019000100303\&lng=en\&nrm=iso. Acesso em: 23 Mar. 2019. DOI:10.1590/0037-8682-0347-2018

8. MEHTA, R. et al. The neurological complications of chikungunya virus: A systematic review. Rev. med. virol., Chichester, v. 28, n. 03, fev. 2018. Disponível em: https://www.ncbi.nlm.nih.gov/pmc/articles/ PMC5969245/pdf/RMV-28-na.pdf. Acesso em: 20 de mar. de 2019. doi:10.1002/rmv.1978

9. ARAUJO, E. S.; BUCHALLA, C. M. O uso da Classificação Internacional de Funcionalidade, Incapacidade e Saúde em inquéritos de saúde: uma reflexão sobre limites e possibilidades. Rev. bras. epidemiol., São Paulo, v. 18, n. 3, p. 720-724, Sept.2015. Disponível em: http://www. scielo.br/scielo.php?script=sci_arttext\&pid=\$1415-790X2015000300 720\&lng=en\&nrm=iso. Acesso em: 05 abr. 2019. DOI: 10.1590/19805497201500030017.

10. SAMPAIO, R. F. APLICAÇÃO DA CLASSIFICAÇÃO INTERNACIONAL DE FUNCIONALIDADE, INCAPACIDADE E SAÚDE (CIF) NA PRÁTICA CLÍNICA DO FISIOTERAPEUTA. Rev. bras. fisiot., Belo Horizonte, v. 9, n. 01, p. 129-136,Out. 2005. Disponível em: http://files.fisioterapiafap.webnode. com/200000012-316bc3265d/CIF\%20BASES.pdf. Acesso em: 05 abr. 2019.

11. WORLD HEALTH ORGANIZATION. Classificação Internacional de Funcionalidade, Incapacidade e Saúde (CIF). Lisboa: Direcção-Geral da Saúde, 2004. 5-225. 
12. FRÉZ, A. R. et al. Proposed use of the international classification of functioning, disability and health to evaluate quality of life after an amputation. Fisiot. Mov., Curitiba, v. 27, n.1, p.49-56, Mar. 2014. DOI:10.1590/0103-5150.027.001.A005. Disponível em: http://www. scielo.br/scielo.php?pid=S0103-51502014000100049\&script=sci_ abstract. Acesso em: 23 Ago. 2019.

13. THIBERVILLE, S. D. et al. Chikungunya fever: a clinical and virological investigation of outpatients on Reunion Island, South-West Indian Ocean. PLos negl. trop. dis., San Francisco, v.7, n.1:e2004, jan. 2017. Disponível em: https://www.ncbi.nlm.nih.gov/pmc/articles/PMC3547841/. Acesso em: 21 Mar. 2019. DOI:10.1371/journal.pntd.0002004.

14. JAVELLE, E.; RIBERA, A. et al. Specific management of postchikungunya rheumatic disorders: a retrospective study of 159 cases in Reunion Island from 2006-2012. PLos negl. trop. dis., San Francisco, v. 9, n. 3:e0003603, Mar. 2015. Disponível em: https://www.ncbi.nlm. nih.gov/pmc/articles/PMC4356515/. Acesso em: 21 Mar. 2019. DOI: 10.1371/journal.pntd.0003603.

15. MATHEW, A. J. et al. Trivandrum COPCORD Study Group. Rheumaticmusculoskeletal pain and disorders in a naïve group of individuals 15 months following a Chikungunya viral epidemic in south India: a population based observational study. Int. j. clin. pract., Oxford, v. 65, n. 12, p. 1306-12, Nov. 2011. Disponível em: https://onlinelibrary.wiley. com/doi/full/10.1111/j.1742-1241.2011.02792.x. Acesso em: 22 Ago. 2019. DOI:10.1111/j.1742-1241.2011.02792.x.

16. REZZA, G.; WEAVER, S. C. Chikungunya as a paradigm for emerging viral diseases: Evaluating disease impact and hurdles to vaccine development. PLos negl. trop. dis., San Francisco, v. 13, n. (1):e0006919, Jan. 2019. Disponível em: https://www.ncbi.nlm.nih.gov/pmc/articles/ PMC6336248/. Acesso em: 22 de Ago. de 2019. DOI: 10.1371/journal. pntd.0006919.

17. YACTAYO, S. et al. Epidemiology of Chikungunya in the Americas. J. Infect. Dis, Baltimore, v. 214, supl. 5, p. S441-S445, dez. 2015. Disponível em: https://www.ncbi.nlm.nih.gov/pmc/articles/PMC5137246/\#_ffn_ sectitle. Acesso em: 22 Ago. 2019. DOI:10.1093/infdis/jiw390.

18. ORGANIZAÇÃO MUNDIAL DA SAÚDE. Como usar a CIF: um manual prático para o uso da Classificação Internacional de Funcionalidade, Incapacidade e Saúde (CIF). Genebra: OMS, 2013. (Versão preliminar para discussão, out. 2013).

19. ZHANG, X. Y. et al. A Preliminary Study of Ankle Single Photon Emission Computed Tomography/ComputedTomography in Patients With Bony Impingement Syndrome: Association With the Visual Analogue Scale Pain Score. J. Foot Ankle Surg., Baltimore, v. 58, n. 3, p. 434-440, Mar. 2019. Disponível em: https://www.jfas.org/article/S1067- 2516(18)30414-9/fulltext. Acesso em: 23 Ago. 2019. DOI: 10.1053/j. jfas.2018.09.010.

20. KURTAIŞ, Y. et al. Reliability, construct validity and measurement potential of the ICF comprehensive core set for osteoarthritis. BMC Musculoskelet. Disord., London, v. 12, p.255, Nov. 2011. Disponível em: https://www.ncbi.nlm.nih.gov/pmc/articles/PMC3228679/. Acesso em: 3 de Ago. de 2019. DOI:10.1186/1471-2474-12-255.

21. MEHDI, Z. et al. Frequency, Awareness, and Symptoms of Chikungunya Among Patients in a Tertiary Care Hospital of Karachi: A Cross-Sectional Study. Cureus, Bethesda, v. 11, n. 2:e4054, Feb. 2019. Disponível em: https://www.researchgate.net/publication/331052795_Frequency_ Awareness_and_Symptoms_of_Chikungunya_Among_Patients_in_a Tertiary_Care_Hospital_of_Karachi_A_Cross-Sectional_Study. Acesso em 23 Ago. 2019. DOI:10.7759/cureus.4054.

22. SOUZA, C. G. et al. Evaluation of pain, functional capacity and kinesiophobia in women in the chronic stage of chikungunya virus infection: a cross-sectional study in northeastern Brazil. Acta Trop., Basel, v.18, p. 31504-3, Dec. 2018. Disponível em: https://www.sciencedirect. com/science/article/abs/pii/S0001706X18315043?via\%3Dihub. Acesso em: 24 Ago. 2019. DOI:10.1016/j.actatropica.2018.12.008.

23. LAGUARDIA, J. et al. Dados normativos brasileiros do questionário Short Form-36 versão 2. Rev. Bras. Epidemiol., São Paulo, v. 16, n. 4 , p.889-897, Dec. 2013. Disponível em: http://www.scielo.br/scielo. php?pid=S1415-790X2013000400889\&script=sci_arttext\&tlng=pt. Acesso em: 24 Ago. 2019. DOI:10.1590/S1415-790X2013000400009.

24. FARR, II J.; MILLER, L. E.; BLOCK, J. E. Quality of life in patients with knee osteoarthritis: a commentary on nonsurgical and surgical treatments. Open Orthop J., United Arabe, v. 7, p. 619-623, Nov. 2013. Disponível em: https://www.ncbi.nlm.nih.gov/m/pubmed/24285987/. Acesso em: 24 Ago. 2019. DOI:10.2174/1874325001307010619.

25. HOOGEBOOM, T. J. et al. Longitudinal impacto $f$ joint pain comorbidity on quality of life and activity levels in kenee osteoarthristis: data from the Osteoarthristis Initiative. Reumatology, Oxford, v. 52, n.3, p. 543-546, Mar. 2013. Disponível em: https://www.ncbi.nlm.nih.gov/ pmc/articles/PMC3716330/\#_ffn_sectitle. Acesso em: 25 Ago. 2019. DOI: 10.1093/rheumatology/kes314.

26. SILVA, L. A; DERMODY, T. S. Chikungunya virus: epidemiology, replication, disease mechanisms, and prospective intervention strategies. J Clin. Invest., New York, v. 127, n.3, p.737-749, Mar. 2017. Disponível em: https://www.ncbi.nlm.nih.gov/pmc/articles/ PMC5330729/\#_ffn_sectitle. Acesso em: 25 ago. 2019. DOI:10.1172/ $\mathrm{JCl} 84417$.

Submetido em: 11/09/2019

Aceito em: $16 / 09 / 2020$ 